\title{
A Fluidizing Column for Extracting Cysts of Heterodera avenae from Soil
}

\author{
R. W. Smiley, Oregon State University, Columbia Basin Agricultural Research Center, Pendleton 97801
}

\begin{abstract}
Smiley, R. W. 2012. A fluidizing column for extracting cysts of Heterodera avenae from soil. Plant Dis. 96:820-826.

The cereal cyst nematode Heterodera avenae can be extracted from soil using several different floatation or elutriation methods. Automated methods are prohibitively expensive for use in small labs and, for optimal efficiency, floatation methods require that the soil be air dried for an extended period. A method which suspends soil particles in a water column above a fluidizing plate was reported as being most efficient with wet and dry soils. Use of the fluidizing column for extracting $H$. avenae has not been reported in the United States and materials to construct the column using contemporary components

column with components available in the United States, and to compare numbers of cysts and eggs plus juveniles (from cysts) extracted by the column and three other floatation methods: Fenwick can, flask, and Cobb sieving. From a soil containing recently produced (more dense) cysts, the column extracted at least $18 \%$ more cysts and $23 \%$ more eggs plus juveniles than the Fenwick and flask methods. The fluidizing column was found to be useful for small laboratories because it is inexpensive ( $\$ 253$ for two columns), easily and quickly constructed by nonprofessional labor, and produces adequately repeatable results.
\end{abstract} have not been described. Objectives of this research were to construct a
Heteroderid cysts have been extracted from soil using a wide array of equipment and procedures, ranging from automated continuous elutriation methods to collection of cysts separated from soil by flotation in water-filled buckets or flasks (20). Construction of equipment for automated methods used by large commercial and public-sector nematology laboratories is prohibitively expensive for small laboratories that process relatively few samples. However, simple flotation procedures often have low uniformity among repetitions and also produce extracts containing cysts amongst large amounts of organic debris (9). Some flotation procedures are more efficient after field soils have been air dried for time periods as long as 3 months (12), causing it to be difficult to attain higher levels of precision in a timely manner. Likewise, flotation procedures are generally less efficient for extracting new cysts than lessdense older cysts, which contain a higher proportion of air (2). Although cysts can be separated from the debris using densitygradient procedures combined with centrifugation, those procedures often rely upon the availability of a centrifuge and they often reduce the hatching efficiency of eggs that are subsequently released from cysts $(17,18)$, making density-gradient separations undesirable when eggs or juveniles are intended to be used as inoculum.

The cereal cyst nematode Heterodera avenae occurs in at least seven western states of the United States and reduces grain yields in the Pacific Northwest states of Idaho, Oregon, and Washington by at least $\$ 3.4$ million annually (21). The cereal cyst nematode $H$. filipjevi is also present in Oregon (21). Small laboratories with few support staff and minimal funding need a cyst extraction procedure that is efficient, simple, inexpensive, and neither requires laborious hand picking nor reduces the viability of eggs that may be destined for use as inoculum in subsequent experiments. Extraction of $H$. avenae cysts at one such lab, at Pendleton, OR, was attempted using a locally constructed Fenwick can (5). Two successive versions of that apparatus exhibited a high rate of variability for extracting cysts from 250 -g subsamples of a well-mixed silt loam and also tended to extract mostly cysts containing very few eggs. It was

Corresponding author: R. W. Smiley,

E-mail: richard.smiley@ oregonstate.edu

Accepted for publication 21 December 2011.

http://dx.doi.org/10.1094/PDIS-10-11-0892

(C) 2012 The American Phytopathological Society previously reported that recovery using the Fenwick can depended on cyst density (19), which varies with age of the cyst. In work in our lab (24), we also encountered similar challenges using the flask method (10) and the Cobb sieving and decanting method (3). Each of these three methods was performed using procedures described by Ingham (9), using a 60-mesh screen with 250- $\mu$ m apertures (1) to retain and concentrate cysts of $H$. avenae.

Trudgill et al. (26) reported that extraction of Heteroderid cysts from both wet and dry soils was more efficient when using a fluidizing column rather than a Fenwick can. They also reported that the fluidizing column extracted a higher proportion of white females and new egg-bearing cysts compared with older cysts containing few or no eggs. Moreover, the fluidizing column produced extracts with minimal flotation debris, making cysts much easier to count and to collect manually compared with extracts using other methods. The fluidizing column was described as being quicker and having fewer potential operator errors than other extraction methods examined. Trudgill et al. (26) concluded that their method "obviously is advantageous where only limited facilities are available." The fluidizing column method of extracting Heteroderid cysts was used successfully in several leading European laboratories during the 1970s and 1980s $(4,13,15,16)$, and an improved version at Rothamstead Experimental Station is shown in Hooper and Evans (8). Kerry (11) reported that that the fluidizing column was more effective than a combination of the Fenwick can plus an elutriation step for extracting cysts from wet and dry silt loams. Although the fluidizing system took longer than the Fenwick can and resulted in dirtier extracts which required longer time intervals for counting the extracted cysts (11), the fluidizing column eliminated the need to dry the soil sample before extracting the cysts, saving time when large numbers of samples were being processed or when rapid assessments of cyst numbers were needed. Confirming the findings of Trudgill et al. (26), Kerry (11) reported that the fluidizing column tended to extract cysts containing more eggs compared with cysts extracted with the Fenwick can. The flask method was particularly inefficient for extracting cysts from silty soils (11). Cooke et al. (4) reported that the fluidizing method provided slightly greater extraction efficiency than the Fenwick can and the Oostenbrink automated elutriator apparatus when extracting cysts of $H$. schachtii from soil.

There do not appear to be any recent reports of extractions using the fluidizing column. Moreover, the construction materials originally described are not current and were based upon components and sizes available in the United Kingdom. The objectives of this research were to (i) construct a fluidizing column that can be con- 
structed using contemporary materials, commonly available in the United States, which do not require specialized machine tools such as those required for sheet metal fabrication, and (ii) calibrate the fluidizing column and compare its operation with other nonautomated procedures such as the Fenwick can, Cobb sieving, and the flask method. Features of interest included the cost and ease of construction for the fluidizing column, and comparisons among methods with respect to number of cysts recovered from naturally infested Pacific Northwest soils, cleanliness of extracted cysts, number of eggs plus juveniles recovered from extracted cysts, and relative amounts of time required to prepare, extract, and count the cysts using each extraction method.

\section{Materials and Methods}

Two fluidizing columns were constructed and, with three other methods, were used to compare the number of Heterodera cysts that could be extracted from three soils. Tests were performed with soils collected from Island City, OR during October 2008; St. Anthony, ID during October 2008 and September 2011; and Imbler, OR during November 2010. Each soil was stored in a galvanized bin outdoors until used in this study. Soils from St. Anthony and Island City were infested with $H$. avenae and the soil from Imbler contained a mixture of $H$. avenae and $H$. filipjevi. These naturally infested soils were described previously $(22-24,28)$. Briefly, the Idaho soil was a St. Anthony gravelly sandy loam and the Imbler and Island City soils were an Alicel loam and an Alicel fine sandy loam, respectively.

Construction of two fluidizing columns. In all, 23 of 26 components required to construct two fluidizing columns (Table 1) were available at a local hardware store (Ace Hardware, Oak Brook, IL). Three components were acquired from suppliers via the internet: O rings (Amazon, Seattle, WA), flow-control valves (Fresh Water Systems, Greenville, SC), and fluidizer plates (PolyStar Technologies, Peachtree City, GA). Excluding a 60-mesh sieve, the expense for constructing two columns, the water supply system, and a mounting panel was $\$ 253$. The two-column fluidizer system was constructed in 2 days using commonly available hand tools (screw driver, pliers, channel lock pliers, skill saw, cross cut saw, hammer, $\mathrm{C}$ clamps, round file, and thread tap) and power tools (drill press, table saw, hand-held drill, and drill bits).

The upper portion of each column (Fig. 1) was constructed as follows. A section of number-125 SDR narrow-wall PVC pipe was cut to a length of $36 \mathrm{~cm}$. A notch was cut out of one end of the pipe to provide a focused discharge of water. The notch was $3.8 \mathrm{~cm}$ deep, $3.8 \mathrm{~cm}$ wide at the top, and $1.3 \mathrm{~cm}$ wide at the bottom. A horizontal stabilizer foot of a PVC sprinkler stand was removed from the central portion of the stand and used to construct the discharge spout. A scroll saw was used to cut material from the large end of the stabilizer foot to provide a tight-fitting discharge spout with an approximate $20^{\circ}$ declining angle. The spout was welded with PVC glue into position at the bottom of the notch in the main column and a small amount of tub caulk was used to seal small gaps of the attachment line. The spout extended $8 \mathrm{~cm}$ from the column perimeter. A 3-cm-deep cylinder was constructed by cutting one end off a PVC coupler. This cylinder was raised onto the bottom of the main column by gentle tapping until $3 \mathrm{~cm}$ of the main column was exposed below the coupler ring. A band of PVC glue was placed onto the main column before the coupler ring

Table 1. Components for constructing two fluidizing columns and a water flow-control system

\begin{tabular}{|c|c|c|c|c|}
\hline List of components ${ }^{v}$ & Quantity & Cost (\$) & Total (\$) & Sourcew $^{w}$ \\
\hline \multicolumn{5}{|l|}{ Two fluidizing columns } \\
\hline PVC pipe, number $125 \mathrm{SDR}, 76 \mathrm{~mm}$ in diameter, $1.2-\mathrm{m}$ long, narrow wall & 1 & 4.36 & 4.36 & $\mathrm{AH}$ \\
\hline PVC 76-mm couplers & 3 & 3.59 & 10.77 & $\mathrm{AH}$ \\
\hline PVC 76-mm end caps & 2 & 4.29 & 8.58 & $\mathrm{AH}$ \\
\hline PVC sprinkler stand ES444 RG $1 \times 3$ & 1 & 4.99 & 4.99 & $\mathrm{AH}$ \\
\hline Package of silicone $\mathrm{O}$ rings (83-mm i.d. $\times 89$-mm o.d.) & 1 & 23.20 & 23.20 & $\mathrm{AM}$ \\
\hline Porous polyethylene diffuser plate ${ }^{\mathrm{x}}$ & 1 & 8.00 & 8.00 & PS \\
\hline Flexible 76-mm rubber coupling with screw clamps & 2 & 7.69 & 15.38 & $\mathrm{AH}$ \\
\hline Threaded hose barbs $(6.4 \times 9.5 \mathrm{~mm})$ & 2 & 1.29 & 2.58 & $\mathrm{AH}$ \\
\hline PVC glue (Weld-0n; 120-ml can) & 1 & 4.39 & 4.39 & $\mathrm{AH}$ \\
\hline Tub/tile caulk, clear, 155 -g tube & 1 & 3.89 & 3.89 & $\mathrm{AH}$ \\
\hline \multicolumn{5}{|l|}{ Water supply and flow valves } \\
\hline Flow control valves ${ }^{y}$ & 2 & 53.62 & 107.24 & FW \\
\hline Garden hose (5-m remnant section) & 1 & 8.99 & 8.99 & $\mathrm{AH}$ \\
\hline Quick coupler for garden hose & 1 & 4.59 & 4.59 & $\mathrm{AH}$ \\
\hline Hose connector with ball valve shut-offs, a ' $\mathrm{Y}$ ' splitter & 1 & 4.99 & 4.99 & $\mathrm{AH}$ \\
\hline Female connectors for garden hose, GT 15-mm BRS & 2 & 2.49 & 4.98 & $\mathrm{AH}$ \\
\hline Male connectors for garden hose, GT 15-mm BRS & 2 & 2.49 & 4.98 & $\mathrm{AH}$ \\
\hline Insert ells $\left(12.7-\mathrm{mm}, 90^{\circ}\right)$ for garden hose & 4 & 1.39 & 5.56 & $\mathrm{AH}$ \\
\hline Galvanized reducing coupling $(12.7 \times 9.5 \mathrm{~mm})$ & 2 & 1.59 & 3.18 & $\mathrm{AH}$ \\
\hline Hose clamps SS number 02/SS screw, for garden hose & 8 & 0.99 & 7.92 & $\mathrm{AH}$ \\
\hline Swivel adaptors $(12.7 \times 9.5 \mathrm{~mm})$ & 2 & 2.39 & 4.78 & $\mathrm{AH}$ \\
\hline Threaded hose barbs $(9.5 \times 9.5 \mathrm{~mm})$ & 2 & 0.99 & 1.98 & $\mathrm{AH}$ \\
\hline Vinyl tubing $(9.5-\mathrm{mm}$ i.d. $\times 14.3-\mathrm{mm}$ o.d. $\times 2$-m long) & 1 & 4.14 & 4.14 & $\mathrm{AH}$ \\
\hline Hose clamps SS number 02/SS screw, for vinyl tubing & 4 & 0.99 & 3.96 & $\mathrm{AH}$ \\
\hline \multicolumn{5}{|l|}{ Support stand for flow valves $\mathrm{z}$} \\
\hline Plywood (18.4-mm thick, $11-\mathrm{cm}$ wide, $0.6-\mathrm{m}$ long) & 1 & $\mathrm{nc}$ & 0.00 & na \\
\hline Wood screws & 15 & $\mathrm{nc}$ & 0.00 & na \\
\hline Aluminum angle iron (18.4-mm sides × 30-cm long) & 1 & $\mathrm{nc}$ & 0.00 & na \\
\hline Total expense & $\ldots$ & $\ldots$ & 253.43 & $\ldots$ \\
\hline
\end{tabular}

${ }^{v}$ Component sizes are presented in approximate metric units, as converted from the American units in which the components of these fluidizing columns are marketed in the United States. Component dimensions available from the suppliers were converted for this table from inches to millimeters (in parenthesis) as follows: 1/4 (6.4), $3 / 8$ (9.5), 1/2 (12.7), 9/16 (14.3), 5/8 (15), 3/4 (18.4), 3 (76), $3.25(83), 3.5$ (89), 4.5 (110).

${ }^{\mathrm{w}} \mathrm{AH}=$ Ace Hardware (Oak Brook, IL; acehardware.com); AM = Amazon (Seattle, WA; amazon.com); FW = Fresh Water Systems (Greenville, SC; freshwatersystems.com); PS = PolyStar Technologies (Peachtree City, GA; polystar-technologies.com); nc $=$ no cost and na = not applicable.

${ }^{\mathrm{x}}$ High-density polyethylene hydrophilic porous plastic disc; Polystar-Technologies.com (discs were cut from a custom-molded 20-cm-diameter disc; $5.2 \mathrm{~mm}$ thick, $150-\mu \mathrm{m}$ pores; designed for a flow rate capacity of up to $126 \mathrm{ml} / \mathrm{s}(1 \mathrm{gallon} / \mathrm{minute}$ [gpm]) through a diffuser plate with a diameter (85 mm; $35 / 16$ in.) used in this fluidizing column).

y Liquatec Adjustable Panel Mount Flowmeter, 63 and $126 \mathrm{ml} / \mathrm{s}$ [= 0.5 and $1 \mathrm{gpm}]) ; 12.7 \mathrm{~mm}$ (1/2-in.) MNPT; FreshWaterSystems.com.

${ }^{z}$ Constructed without cost using scrap materials commonly available in most wood shops. 
reached its final position, welding the ring to the perimeter of the main column. The coupler ring would later serve as an anchoring point with the same diameter as the base unit (described later) when a flexible rubber coupler was installed to prevent separation of the column from the base unit when the unit became pressurized with water.

The removable base unit was constructed by gluing a PVC end cap into a PVC coupler. A threaded hose barb was inserted into the base by drilling a hole $110 \mathrm{~mm}$ (7/16 in.) in diameter through the side wall of the base, above the ridge of the end cap, and using a 1/4-18 tap to install pipe threads into the hole. A threaded hose barb was screwed into the hole. An $\mathrm{O}$ ring was placed onto the ridge at the midpoint of the inside of the coupler. An 84-mm diameter disk of porous diffuser plate was cut from the 20-cm-diameter disk provided by the manufacturer. The diffuser disk was placed into the base, over the $\mathrm{O}$ ring, and then the perimeter of the disk was covered by a second $\mathrm{O}$ ring. A flexible rubber coupler was placed over the upper portion of the assembled base unit and was pressed down until only the upper half of the flexible coupler remained exposed above the base unit. The upper column section was then inserted into the base unit and tapped down to assure firm contact between the diffuser plate and the $\mathrm{O}$ rings, and then the two units were secured by tightening the screws of the flexible rubber coupler.

A stand for mounting two flow-control valves and water supply fittings (Fig. 1) was constructed of plywood and was sealed with polyethylene varnish. The stand was $48 \mathrm{~cm}$ high. Two strips of $18.4 \mathrm{~mm}(3 / 4-\mathrm{in}$.) angle iron were mounted horizontally at the upper end of the stand and were spaced to facilitate the mounting of the flow-control valves. Holes were drilled near each end of the angle iron strips for insertion of the bolts fabricated into the back of each flow-control valve. Standard sections of garden hose and appropriate fittings (Table 1) were used to connect the flow-control valves to a water faucet. A hosesplitter with a single input port and ball valves for each of the two discharge ports was used to provide regulation of water to each of the flow-control valves mounted on the stand. Threaded hose barbs were attached to the discharge port of each flowcontrol valve and vinyl tubing was used to connect the valve to the input barb at the base of each fluidizing column. Each hose connection was clamped to prevent blow outs when water was introduced into the system. Water pressure measured during operation was $380 \mathrm{kPa}$.
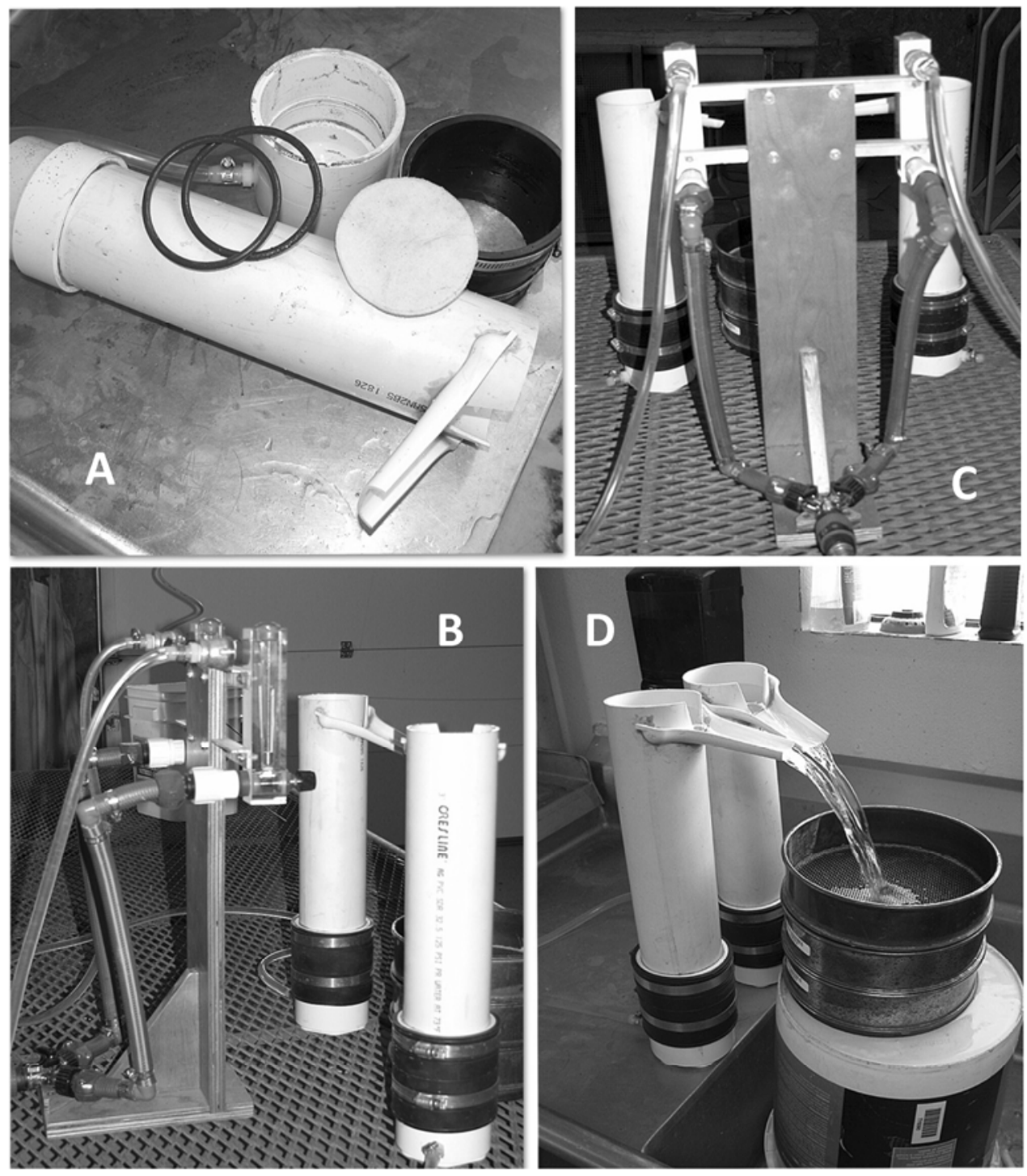

Fig. 1. Assembly and operation of a fluidizing column for extracting cysts of Heterodera avenae from soil. A, Assembly of the upper and base units; the upper unit has a notch and spout to discharge water and a retaining ring near the bottom, and the base unit contains two O-rings and a porous plate. B, Side view showing two fluidizing columns, flow-control valves, water supply system, and flexible rubber coupling to prevent separation of the upper unit and the base unit when water under pressure is injected into the base unit. C, Detail of water supply system including quick coupler connection for a garden hose, a ' $Y$ ' splitter assembly with two ball valves, plumbing to transmit water into the base of the flow-control valves, and vinyl tubing to transmit water from each flow control valve into a fluidizing column. D, Two fluidizing columns being operated at a water injection rate of $63 \mathrm{ml} / \mathrm{s}$ ( 0.5 gallons/minute). 
The flow-control valves and the ball valves on the hose splitter were turned to the off position before the water supply was turned on at the faucet. Soil was screened through a 2-mm sieve and dumped onto the top of the porous fluidizer plate in the column. The ball valves were slowly turned on and then the flow-control valves were opened until the float bubble indicated a desired rate of flow.

Calculations to calibrate the fluidizing column. Calibration of the column required a calculation to determine the minimal rate of rise of water in the column to overcome the anticipated settling velocity of cysts of $H$. avenae and $H$. filipjevi. Trudgill et al. (26) calculated that a terminal velocity of $1.3 \mathrm{~cm} / \mathrm{s}$ was required to elutriate cysts of Globodera rostochiensis which have cyst widths of 250 to $810 \mu \mathrm{m}$. Two formulas were used to estimate the rate of settling of cysts of $H$. avenae and $H$. filipjevi for these experiments. The formula described by Trudgill et al. (26) was $V=g(\mathrm{Sp}-$ $\mathrm{Sl}) D^{2} / 28 \eta$, where $V$ is terminal velocity $(\mathrm{cm} / \mathrm{s}), g$ is acceleration due to gravity $\left(981 \mathrm{~cm} / \mathrm{s}^{2}\right), D$ is diameter of the cyst width $(\mathrm{cm}), \mathrm{Sp}$ is the estimated specific gravity of a gravid cyst, $\mathrm{Sl}$ is specific gravity of water $\left(0.998\right.$, at $\left.23^{\circ} \mathrm{C}\right)$, and $\eta$ is the viscosity of water $\left(0.00936\right.$ poises, at $\left.23^{\circ} \mathrm{C}\right)$. The Trudgill formula was an early variant of the current Stoke's Law (6), calculated as $V=g(\mathrm{Sp}-$ Sl) $D^{2} / 18 \eta$.

Cysts of $H$. avenae are lemon shaped with a conical terminus and have been reported to have diameters at the widest point of 390 to $725 \mu \mathrm{m}$ (7), 360 to $500 \mu \mathrm{m}$ (27), and 408 to $744 \mu \mathrm{m}$ (25). Cysts of $H$. filipjevi have a similar shape and have diameters of 340 to $620 \mu \mathrm{m}$ (7), 480 to $672 \mu \mathrm{m}$ (25), or 395 to $619 \mu \mathrm{m}$ (23). For the purposes of calculations for this study, cyst diameters were assumed to be 400 to $800 \mu \mathrm{m}$ for $H$. avenae and 300 to $700 \mu \mathrm{m}$ for $H$. filipjevi. The specific gravity of cysts was assumed to be 1.07 to 1.08 , as reported from measurements of $G$. rostochiensis by Trudgill et al. (26). Terminal velocities (rate of settling) for the smallest and largest females of $G$. rostochiensis examined by Trudgill et al. (26), with cyst widths of 300 and $700 \mu \mathrm{m}$, were calculated to be 0.9 and $2.1 \mathrm{~cm} / \mathrm{s}$, respectively. However, those authors measured actual settling rates for G. rostochiensis females of those sizes at 0.4 and $1.3 \mathrm{~cm} / \mathrm{s}$, indicating that the calculation derived for spherical objects overestimated the rate of rise of water required to elutriate the smallest and largest females of that species by 56 and $38 \%$, respectively. This discrepancy is presumed to be due to the nonspherical shape and the surface properties of these cysts (14) which cause them to lack conformance with physical laws governing the settling rates for perfectly smooth and spherical objects in aqueous suspensions (6). Moreover, cysts contain variable volumes of air, and may also contain a waxy surface.

Calibration of the fluidizing column. Eight replicated runs using water at various flow rates (milliliters/second, as actually measured by the flow meters in gallons/minute [gpm]), were conducted to determine the rate of rise in the water columns. Rates greater than the calculated cyst settling velocity $(V)$ were used for subsequent comparisons of extraction methods.

Comparisons of cyst extraction methods. Four experiments were performed to compare extractions of cysts and, in three experiments, of eggs plus juveniles contained in the cysts. Three soils were used for two experiments and one soil was used in each of two other experiments.

Experiment 1. Five methods were used to extract $H$. avenae cysts from an Alicel fine sandy loam during August 2010, using four replicates of $250-\mathrm{g}$ subsamples for each method. The fluidizing column operated at two flow rates $(63$ and $126 \mathrm{ml} / \mathrm{s}[=0.5$ and $1 \mathrm{gpm}]$ ) and was compared with the Fenwick can, flask, and Cobb sieving methods. The fluidizing column was operated as described by Trudgill et al. (26) and the other methods followed procedures described by Ingham (9). The Fenwick can was constructed locally and operated without the additional elutriation step to process residual soil that settled to the bottom of the can, as described by Ingham (9). The Fenwick can used in our lab had top and bottom diameters of 9 and $18 \mathrm{~cm}$, respectively, and a height of $45 \mathrm{~cm}$. The top and bottom dimensions were similar to those described by
Fenwick (5) but our can was $15 \mathrm{~cm}$ higher than the can described by Fenwick. The neck of the funnel for our extraction device consisted of a tube having a 3-cm internal diameter and a length of 29 $\mathrm{cm}$. This extended length of the discharge tube for the funnel resulted from poor experiences with earlier extractions using a shorter discharge tube. For work described in this article, water and soil were ejected out of the neck about $16 \mathrm{~cm}$ above the base of the can, or approximately $10 \mathrm{~cm}$ closer to the base than was described by Fenwick (5).

Cysts extracted by each method were collected on a 60-mesh $(250-\mu \mathrm{m})$ screen and washed onto a filter paper for counting. Multiple filter papers were used when extracts included a large amount of organic debris. Numbers of cysts and the amount of time required and the cleanliness of extracted cysts were recorded for each extraction method.

Experiment 2. The fluidizing column was operated at two flow rates $(63$ and $126 \mathrm{ml} / \mathrm{s})$ for comparisons with the Fenwick can and flask methods for extracting $H$. avenae and $H$. filipjevi cysts from an Alicel fine sandy loam, an Alicel loam, and a St. Anthony gravelly sandy loam during July 2011, using four replicates of 250-g subsamples for each method. Cysts were collected and counted as described for experiment 1 . The cysts were then washed onto a 100 -mesh $(150-\mu \mathrm{m})$ screen and macerated by gentle rubbing with a rubber stopper to release eggs plus juveniles (1). Eggs and juveniles were washed through the screen and collected in a pan, and the number of eggs plus juveniles in the suspension was estimated using three replicates of 1-ml aliquots that were transferred to a counting slide.

Experiment 3. The repeatability of two extraction methods was examined by extracting four additional replicates of the three soils previously evaluated in experiment 2 . Methods for this experiment included the fluidizing method (at $63 \mathrm{ml} / \mathrm{s}$ ) and the Fenwick can.

Experiment 4. Because soils used in previous experiments had been stored for several years, the four extraction methods were evaluated again to compare numbers of cysts and eggs plus juveniles that could be extracted from a soil that was newly collected from a current crop of spring wheat that was being heavily damaged by $H$. avenae at St. Anthony. The soil was collected in September 2011 and soil plus wheat roots were stored in a field moist condition at $4^{\circ} \mathrm{C}$. In October 2011 , the old and new cysts in the soil were supplemented with additional new cysts by gently rubbing wheat roots collected with that soil to separate additional new cysts still embedded in the roots. Those cysts were placed into to soil which was then passed through a $2-\mathrm{mm}$ screen, mixed thoroughly, and subdivided into 16 subsamples for replicated extractions using four methods: the fluidizing column operated at two flow rates, the Fenwick can, and the flask method.

Statistical analysis. Counts of cysts and egg plus juveniles in experiments 1 and 4 were analyzed individually using univariate analysis of variance (ANOVA) with extraction method as treatment and replicates as blocks. Data in experiments 2 and 3 were analyzed using two-way ANOVA with extraction methods and soils as treatments and replicates as blocks. Analyses were performed using CoStat Statistical Software (Co-Stat v. 6.400; CoHort Software, Monterey, CA). When treatment means were significant at $P<$ 0.10 , means were separated using the Tukey's honestly significant difference (HSD) test. Standard errors of the mean were also calculated and reported.

\section{Results and Discussion}

Using the formula provided by Trudgill et al. (26), the calculated settling velocities $(V)$ for cysts of $H$. avenae were 0.43 to $1.72 \mathrm{~cm} / \mathrm{s}$ for cysts with widths of 400 and $800 \mu \mathrm{m}$, respectively. The calculated velocities for $H$. filipjevi were 0.24 to $1.32 \mathrm{~cm} / \mathrm{s}$ for cysts with widths of 400 and $800 \mu \mathrm{m}$, respectively. Calculations based upon Stokes Law (6) indicated maximum estimated settling velocities of 2.68 and $2.05 \mathrm{~cm} / \mathrm{s}$ for cysts of $H$. avenae and H. filipjevi, respectively. In recognition that these calculations were previously shown to overestimate actual settling rates by approximately $50 \%$ (26), the targeted maximum rate of rise for water in the fluidizing col- 
Table 2. Comparison of five methods of extracting cysts of Heterodera avenae from 250-g samples of Alicel fine sandy loam; experiment 1

\begin{tabular}{|c|c|c|c|c|c|}
\hline \multirow[b]{2}{*}{ Parameter } & \multicolumn{2}{|c|}{ Column (and flow rate) $)^{y}$} & \multirow[b]{2}{*}{ Fenwick can } & \multirow[b]{2}{*}{ Flask } & \multirow[b]{2}{*}{ Cobb sieving } \\
\hline & $63 \mathrm{ml} / \mathrm{s}$ & $126 \mathrm{ml} / \mathrm{s}$ & & & \\
\hline Cysts recovered $(\text { mean } \pm \mathrm{SE})^{\mathrm{z}}$ & $162 \pm 8$ & $180 \pm 16$ & $145 \pm 15$ & $154 \pm 7$ & $150 \pm 11$ \\
\hline \multicolumn{6}{|l|}{ Time required (minutes) to } \\
\hline Prepare the system & 5 & 5 & 5 & $30-60$ & $5-10$ \\
\hline Conduct the extraction & $7-10$ & $7-10$ & $5-8$ & $7-10$ & $10-15$ \\
\hline Count the cysts & $10-15$ & $10-15$ & $10-15$ & $10-15$ & $45-60$ \\
\hline Complete a procedure & $22-30$ & $22-30$ & $20-28$ & $47-85$ & $60-85$ \\
\hline \multicolumn{6}{|l|}{ Filter papers } \\
\hline Number needed & 1 & 1 & 1 & 1 & $3-5$ \\
\hline Amount of debris & Very little & Very little & Very little & Very little & Excessive \\
\hline Ease of counting cysts & Easy & Easy & Easy & Easy & Very hard \\
\hline
\end{tabular}

y Water injection rate was actually measured in the American units scribed into the flow meter: $63 \mathrm{ml} / \mathrm{s}(=0.5$ gallons $/ \mathrm{minute})$.

${ }^{\mathrm{z}}$ Means did not differ at $\alpha<0.10$, as determined by Tukey's honestly significant difference test; $P=0.3818$. SE $=$ standard error of the mean.

Table 3. Comparison of four extraction methods for recovering Heterodera cysts and eggs plus juveniles (from cysts) from 250-g samples of three soils; experiment $2^{\mathrm{y}}$

\begin{tabular}{|c|c|c|c|c|c|c|}
\hline \multirow[b]{2}{*}{ Method and column flow rate } & \multicolumn{3}{|c|}{ Cysts } & \multicolumn{3}{|c|}{ Eggs + juveniles } \\
\hline & SAGSL & $\mathbf{A L}$ & AFSL & SAGSL & $\mathbf{A L}$ & AFSL \\
\hline Column at $63 \mathrm{ml} / \mathrm{s}$ & 627 & $96 \mathrm{~b}$ & $178 \mathrm{ab}$ & 6,880 & $570 \mathrm{a}$ & $810 \mathrm{a}$ \\
\hline Column at $126 \mathrm{ml} / \mathrm{s}$ & 639 & $121 \mathrm{a}$ & $192 \mathrm{a}$ & 7,740 & $620 \mathrm{a}$ & $1,110 \mathrm{a}$ \\
\hline Fenwick can & 615 & $110 a b$ & $157 \mathrm{bc}$ & 6,655 & $54 \mathrm{c}$ & $267 \mathrm{~b}$ \\
\hline Flask & 602 & $95 \mathrm{~b}$ & $134 \mathrm{c}$ & 4,610 & $300 \mathrm{~b}$ & $740 \mathrm{a}$ \\
\hline Overall mean & 621 & 106 & 165 & 6,471 & 386 & 729 \\
\hline $\mathrm{HSD}_{0.05}$ & NS & 15.9 & 28.2 & NS & 240.8 & 456.0 \\
\hline$P>F$ & 0.2912 & 0.0138 & 0.0061 & 0.1383 & 0.0016 & 0.0167 \\
\hline $\mathrm{CV}(\%)$ & 4.2 & 9.4 & 10.7 & 26.6 & 39.0 & 39.1 \\
\hline
\end{tabular}

${ }^{y}$ St. Anthony gravelly sandy loam (SAGSL) from St. Anthony, ID (Heterodera avenae); Alicel loam (AL) from Imbler, OR (mixture of $H$. avenae and $H$. filipjevi); and Alicel fine sandy loam (AFSL) from Island City, OR (H. avenae). Means among extraction methods were separated by Tukey's honestly significant difference (HSD) test. Means followed by the same letter did not differ at $\alpha<0.05$. NS = not significant.

${ }^{\mathrm{z}}$ Water injection rate was measured in the American units shown on the flow meter: $63 \mathrm{ml} / \mathrm{s}$ ( $=0.5$ gallons $/$ minute $)$. CV $=$ coefficient of variation.

umn during this research was adjusted to $1.3 \mathrm{~cm} / \mathrm{s}$. The columns had internal diameters of $83.5 \mathrm{~mm}$ and the rate of rise in the water column was measured at $0.51 \mathrm{~cm} / \mathrm{s}$ (standard deviation $[\mathrm{SD}]=$ $0.01)$ and $1.13 \mathrm{~cm} / \mathrm{s}(\mathrm{SD}=0.02)$ for flow rates regulated by the flow meter at 63 and $126 \mathrm{ml} / \mathrm{s}$, respectively. These measured rates of rise in the water column matched the theoretical rates calculated as 0.57 and $1.15 \mathrm{~cm} / \mathrm{s}$, and were used for further comparisons.

In experiment 1 , the number of cysts extracted from the Alicel fine sandy loam did not differ significantly among the five extraction methods (Table 2). However, there was a tendency to recover slightly more cysts by the fluidizing column operated at $126 \mathrm{ml} / \mathrm{s}$ compared with the other four methods. The column, Fenwick can, and flask methods produced extracts with much less debris than the Cobb sieving method. Half as much time was required to prepare, operate, and count cysts for the fluidizing column and Fenwick can compared with the flask and Cobb sieving methods.

In experiment 2, cysts were extracted from three soils using four extraction methods (Table 3 ). When averaged across methods, the mean number of cysts extracted from Anthony gravelly sandy loam, Alicel fine sandy loam, and Alicel loam differed significantly at $P<0.0001\left(\mathrm{HSD}_{0.05}=13\right)$. When averaged across soils, the mean number of cysts extracted by the fluidizing column operated at $126 \mathrm{ml} / \mathrm{s}$ exceeded that of the column operated at $63 \mathrm{ml} / \mathrm{s}$ and of the Fenwick and flask methods: 318, 300, 294, and 277 cysts per $250 \mathrm{~g}$ of soil, respectively $\left(P<0.0001 ; \mathrm{HSD}_{0.05}=15\right)$. There was no significant soil-method interaction $(P=0.2802)$. For individual soils, numbers of cysts extracted differed significantly among methods for the Alicel loam and Alicel fine sandy loam but not for the more densely infested St. Anthony gravelly sandy loam (Table $3)$. For the Alicel loam, more cysts were extracted using the column at $126 \mathrm{ml} / \mathrm{s}$ than the column at $63 \mathrm{ml} / \mathrm{s}$ and the flask method. For the Alicel fine sandy loam, the column at $126 \mathrm{ml} / \mathrm{s}$ extracted more cysts than the Fenwick and flask methods.

Mean numbers of eggs plus juveniles recovered in experiment 2 by the four extraction methods (Table 3 ) were significantly greater from the St. Anthony gravelly sandy loam than from the Alicel fine sandy loam and the Alicel loam $\left(P<0.0001 ; \mathrm{HSD}_{0.05}=674\right)$. The mean numbers of eggs plus juveniles extracted by the four methods also differed significantly when averaged across soils. The fluidizing column operated at $126 \mathrm{ml} / \mathrm{s}$ extracted significantly more eggs plus juveniles than the Fenwick and flask methods $(3,153,2,325$, and 1,883 eggs plus juveniles, respectively; $P<0.0141 ; \mathrm{HSD}_{0.05}=$ 778 ), and intermediate numbers were extracted by the column operated at $63 \mathrm{ml} / \mathrm{s}$ (2,753 eggs plus juveniles). There was a significant soil-method interaction with respect to extractions of eggs plus juveniles in this experiment $(P<0.0502)$. For individual soils, numbers of cysts extracted differed significantly among methods for the Alicel loam and Alicel fine sandy loam but not for the more densely infested St. Anthony gravelly sandy loam (Table $3)$. For the Alicel loam, more cysts were extracted using the column at 63 and $126 \mathrm{ml} / \mathrm{s}$ than the Fenwick and flask methods. For the Alicel fine sandy loam, the column at 63 and $126 \mathrm{ml} / \mathrm{s}$ extracted more cysts than the Fenwick method, with the flask method being intermediate. These findings indicated that the fluidizing method was more efficient than the Fenwick can for extracting cysts containing juveniles and eggs.

Results from cyst extractions from three soils by two methods, in experiment 3 (Table 4), were similar to those for experiment 2 , except that extractions of cysts and of eggs plus juveniles (from cysts) did not differ at $\alpha=0.10$. Differences in numbers of cysts extracted from each soil by each procedure in experiment 3 varied by 3 to $14 \%$ from the numbers extracted using the same methods and soils used in experiment 2 . However, much greater variability occurred for numbers of eggs plus juveniles detected in these two experiments. Depending on soil, differences in numbers of eggs plus juveniles extracted by the Fenwick can were 12 to $89 \%$ higher in experiment 3 than in experiment 2 . The range of difference was narrower for extractions made by the fluidizing column, with numbers detected in experiment 3 being 16\% higher than in experiment 2 for the St. Anthony gravelly sandy loam, 21\% lower for the 
Table 4. Comparison of two extraction methods for recovering Heterodera cysts and eggs plus juveniles (from cysts) from 250-g samples of three soils; experiment $3^{\mathrm{x}}$

\begin{tabular}{lcc}
\hline Parameter and soil $^{\mathbf{y}}$ & Fluidizing column $^{\mathbf{z}}$ & Fenwick can \\
\hline Cysts & & \\
SAGSL & $683 \pm 26$ & $650 \pm 27$ \\
AL & $89 \pm 5$ & $102 \pm 7$ \\
ALFSL & $153 \pm 6$ & $152 \pm 6$ \\
Eggs + juveniles & & \\
SAGSL & $8,225 \pm 1,578$ & $7,600 \pm 3,893$ \\
AL & $450 \pm 185$ & $475 \pm 180$ \\
ALFSL & $1,800 \pm 123$ & $1,600 \pm 147$ \\
\hline
\end{tabular}

${ }^{x}$ Means of cysts or eggs plus juveniles for each extraction method did not differ at $\alpha<0.10$, as determined by Tukey's honestly significant difference test; $P=0.0599$ for cysts and $P=0.8541$ for eggs plus juveniles. Means are followed by the standard error of the mean.

y St. Anthony gravelly sandy loam (SAGSL) from St. Anthony, ID (Heterodera avenae); Alicel loam (AL) from Imbler, OR (mixture of $H$. avenae and $H$. filipjevi); and Alicel fine sandy loam (AFSL) from Island City, OR (H. avenae).

${ }^{\mathrm{z}}$ Water injection rate was $63 \mathrm{ml} / \mathrm{s}(0.5$ gallons/minute $)$.

Alicel loam, and 55\% higher for the Alicel fine sandy loam. These results demonstrated general agreement with respect to general population densities in soil but also the considerable difference that can occur among extractions that are repeated at different time intervals and by different workers.

In experiment 4 , using a recently collected St. Anthony gravelly sandy loam for which the density of cysts was enhanced by releasing cysts that were embedded in roots, the four extraction procedures varied significantly with respect to numbers of cysts and of eggs plus juveniles that were extracted (Table 5). The two fluidizing methods extracted significantly more cysts than the flask method, and the Fenwick can was intermediate. Each of the column methods extracted higher numbers of eggs plus juveniles than the Fenwick can, and the flask method was intermediate. This experiment demonstrated an overall higher proficiency of the fluidizing column for extracting cysts from a soil that contained a relatively high density of eggs plus juveniles (at least 13,680/kg of soil) derived from newly formed as well as older cysts.

The precision of the fluidizing column described here may have become even greater if it had been constructed with transparent PVC pipe, as was originally suggested by Trudgill et al. (26). Columns used in European laboratories $(4,11,26)$ were each constructed with a transparent cylindrical column that allowed the operator to adjust the rate of water injection to achieve a visually optimal level of suspension and stirring for each soil. The column used in these experiments was constructed with opaque materials that prevented direct observation of floatation of soil particles above the fluidizing plate in the base of the column. An ability to visualize the amount of floatation occurring for soils of differing textures allows the user to customize the rate of water injection in a manner that facilitates more accurate delivery of cysts into the sieve without also floating a significant amount of soil into the sieve. Transparent PVC pipe is available in the United States but was not locally available at outlets where supplies were purchased for the columns constructed here. Although customized flow rates for each extraction may increase overall performance, it may also make it difficult to directly compare extraction methods over multiple extractions unless similar optimizing adjustments are made for individual extractions using each of the other methods being evaluated. In experiments reported here, it was possible to make direct comparisons of two standardized flow rates using different soil types and to repeat those flow rates among repetitions of experiments.

This research indicates that the fluidizing column will be useful for small laboratories because it is inexpensive, easily constructed, repeatable, and delivers relatively clean cysts of $H$. avenae from soils commonly encountered in the Pacific Northwest. The column delivered numbers of cysts comparable with or greater than other
Table 5. Comparison of four extraction systems for recovering Heterodera cysts and eggs plus juveniles (from cysts) from 250-g samples of a St. Anthony gravelly sandy loam from St. Anthony, ID; experiment $4^{\mathrm{y}}$

\begin{tabular}{llc}
\hline Method $^{\mathbf{z}}$ & Cysts & Eggs + juveniles \\
\hline Column at $63 \mathrm{ml} / \mathrm{s}$ & $922 \mathrm{a}$ & $3,420 \mathrm{a}$ \\
Column at $126 \mathrm{ml} / \mathrm{s}$ & $940 \mathrm{a}$ & $3,140 \mathrm{ab}$ \\
Fenwick can & $781 \mathrm{ab}$ & $1,680 \mathrm{c}$ \\
Flask & $698 \mathrm{~b}$ & $1,980 \mathrm{bc}$ \\
Mean & 835 & 2,555 \\
$\mathrm{HSD}_{0.10}$ & 164 & 1,286 \\
$P>F$ & 0.0220 & 0.0854 \\
$\mathrm{CV}(\%)$ & 14.4 & 44.7 \\
\hline
\end{tabular}

${ }^{y}$ Means among extraction methods were separated by Tukey's honestly significant difference (HSD) test. Means followed by the same letter did not differ at $\alpha<0.10$.

${ }^{z}$ Water injection rate was measured in the American units shown on the flow meter: $63 \mathrm{ml} / \mathrm{s}=0.5$ gallons $/$ minute $. \mathrm{CV}=$ coefficient of variation.

nonautomated extraction methods for soils which had been stored for up to several years prior to being processed. The fluidizing column was superior to the Fenwick can and the flask methods for extractions of cysts from a newly collected soil that contained a higher density of recently produced cysts, as was reported previously $(4,11,26)$.

\section{Acknowledgments}

I thank J. Gourlie, S. Goff, and N. Webster for providing technical assistance; and PolyStar Technologies for providing a complementary custom-fabricated fluidizer plate used in columns evaluated in these experiments and an estimate of the expense for a similar plate that may be ordered by other potential users.

\section{Literature Cited}

1. Acedo, J. R., and Dropkin, V. H. 1982. Technique for obtaining eggs and juveniles of Heterodera glycines. J. Nematol. 14:418-420.

2. Caswell, E. P., Thomason, I. J., and McKinney, H. E. 1985. Extraction of cysts and eggs of Heterodera schachtii from soil with an assessment of extraction efficiency. J. Nematol. 17:337-340.

3. Cobb, N. A. 1918. Estimating the nema population of the soil. Agric. Tech Circ. 1. Bureau of Plant Industries, United States Department of Agriculture, Washington, DC.

4. Cooke, D. A., Mathias, P. L., Chwarszczynska, D. M., and Coppock, L. J. 1983. Comparison of methods of assessing field populations of Heterodera schachtii. Plant Pathol. 32:339-343.

5. Fenwick, D. W. 1940. Methods for the recovery and counting of cysts of Heterodera schachtii from soil. J. Helminthol. 18:155-172.

6. Gee, G. W., and Bauder, J. W. 1986. Particle-size analysis. Pages 383-411 in: Methods of Soil Analysis, Part 1. Physical and Mineralogical Methods. A. Klute, ed. American Society of Agronomy, Madison, WI.

7. Handoo, Z. A. 2002. A key and compendium to species of the Heterodera avenae group (Nematoda: Heteroderidae). J. Nematol. 34:250-262.

8. Hooper, D. J., and Evans, K. 1993. Extraction, identification and control of plant parasitic nematodes. Pages 1-60 in: Plant Parasitic Nematodes in Temperate Agriculture. K. Evans, D. L. Trudgill, and J. M. Webster, eds. CAB International, Wallingford, UK.

9. Ingham, R. E. 1994. Nematodes. Pages 459-490 in: Methods of Soil Analysis, Part 2. Microbiological and Biochemical Properties. R. W. Weaver, ed. American Society of Agronomy, Madison, WI.

10. Jones, F. G. W. 1945. Soil populations of beet eelworm (Heterodera schachtii Schm.) in relation to cropping. Ann. Appl. Biol. 32:351-380.

11. Kerry, B. R. 1975. The extraction of cysts of the cereal cyst nematode, Heterodera avenae, from soil. Nematologica 21:163-168.

12. Kerry, B. R., and Hague, N. G. M. 1974. The invasion and development of the cereal cyst-nematode, Heterodera avenae in the roots of autumn- and spring-sown cereals. Ann. Appl. Biol. 78:319-330.

13. Kerry, B. R., and Jenkinson, S. C. 1976. Observations on emergence, survival, and root invasion of second-stage larvae of the cereal cyst nematode Heterodera avenae. Nematologica 22:467-474.

14. Mulvey, R. H., and Golden, A. M. 1983. An illustrated key to the cyst-forming genera and species of Heteroderidae in the Western Hemisphere with species morphometrics and distribution. J. Nematol. 15:1-59.

15. Price, N. S., Clarkson, D. T., and Hague, N. G. M. 1983. Effect of invasion by cereal cyst nematode (Heterodera avenae) on the growth and development of the seminal roots of oats and barley. Plant Pathol. 32:377-383.

16. Price, N. S., and Hague, N. G. M. 1981. The invasion of root tips of cereals by the cereal cyst nematode Heterodera avenae. Ann. Appl. Biol. 99:301-306.

17. Rajan, and Swarup, G. 1982. An evaluation of techniques of extraction and separation from cysts of Heterodera avenae and H. zeae. Indian J. Nematol. 12:132-146. 
18. Rajan, and Swarup, G. 1985. Evaluation of cyst extraction techniques and their effect on biology of Heterodera cajani. Indian J. Nematol. 15:75-82.

19. Reilly, J. J., and Grant, C. E. 1985. Seasonal fluctuations of Globodera tabacum solanacearum as estimated by two soil extraction techniques. J. Nematol. 17:354-360.

20. Shepherd, A. M. 1986. Extraction and estimation of cyst nematodes. Pages 31-49 in: Laboratory Methods for Work with Plant and Soil Nematodes. J. F. Southey, ed. Ministry of Agriculture, Fisheries and Food, London.

21. Smiley, R. W. 2009. Occurrence, distribution and control of Heterodera avenae and $H$. filipjevi in the western USA. Pages 35-40 in: Cereal Cyst Nematodes: Status, Research and Outlook. I. T. Riley, J. M. Nicol, and A. A. Dababat, eds. CIMMYT, Ankara, Turkey.

22. Smiley, R. W., Marshall, J. M., and Yan, G. P. 2011. Effect of foliarly applied spirotetramat on reproduction of Heterodera avenae on wheat roots. Plant Dis. 95:983-989.
23. Smiley, R. W., Yan, G. P., and Handoo, Z. A. 2008. First record of the cyst nematode Heterodera filipjevi on wheat in Oregon. Plant Dis. 92:1136.

24. Smiley, R. W., Yan, G. P., and Pinkerton, J. N. 2011. Resistance of wheat, barley and oat to Heterodera avenae in the Pacific Northwest USA. Nematology 13:539-552.

25. Subbotin, S. A., Sturhan, D., Rumpenhorst, H. J., and Moens, M. 2003 Molecular and morphological characteristics of the Heterodera avenae species complex (Tylenchida: Heteroderidae). Nematology 5:515-538.

26. Trudgill, D. L., Evans, K., and Faulkner, G. 1973. A fluidising column for extracting nematodes from soil. Nematologica 18:469-475.

27. Williams, T. D., and Siddiqi. 1972. Heterodera avenae. C.I.H. Descriptions of Plant-Parasitic Nematodes. Set 1, No. 2. St. Albans, Herts, England.

28. Yan, G. P., and Smiley, R. W. 2010. Distinguishing Heterodera filipjevi and $H$. avenae using polymerase chain reaction-restriction fragment length polymorphism and cyst morphology. Phytopathology 100:216-224. 